\section{The Planetary Collegium: Master Plan for a Distributed Mixed Reality Campus}

\section{Peter Anders, Ph.D.}

\begin{abstract}
This paper describes the design for a Mixed Reality campus for the Planetary Collegium. The Collegium is an international research network centered at Plymouth, U.K. Its plans call for seven sub-centers, or nodes, to be built indifferent parts of the world. These nodes would be linked by shared virtual spaces and digital networks. The paper describes how the Collegium's seeming contradictions (distributed/unified, simulated/physical, local/remote) can be reconciled. The resulting project is a mixed reality that transcends scales from global to local and, ultimately, to the constituent buildings and their digital spaces.
\end{abstract}

\section{I ntroduction}

Among the more vexing questions posed by digital, virtual architecture is its potential effect on the built environment. If, as research suggests, simulation can reduce - even eliminate - the need for construction, what might its effect be on architecture? This question has a history that goes back over twenty years when architects first were confronted with virtual reality, cyberspace and spatialized digital networks. [Benedikt, 1991] [Schmitt, 1993]

Since then the Internet has become increasingly spatial. Computer games have become compellingly interactive and three-dimensional. Alphaworld - the first on-line graphic World - has been supplanted by Second Life and Massive Multi-User Online Role-Playing Games. Mixed, or Augmented Reality, the collocation of simulated and physical objects and spaces, now transcends both virtual and physical realities. Yet, even with all these advances, our question remains.

Several years ago, in an attempt to address it, I undertook the design for a campus for the Planetary Collegium. Originally part of my doctoral dissertation, it remains an actual project presently being considered for development. The program of the project lends itself to a blend of virtual and physical spaces. It presents a new form of learning institution, one distributed globally, yet unified through electronic networks and periodic meetings. This institution the Planetary Collegium - is the vision of Roy Ascott, an internationally recognized leader in the field of interactive media arts and founder/director of the CAiiA-STAR center. As CAiiA-STAR was the direct precursor of the Collegium, it helps to understand how CAiiA-STAR operated.

\section{CAIiA-STAR}

Established during the 1990's, CAiiA-STAR comprised two centers. The Center for Advanced Inquiry in the Interactive Arts, CAiiA, was based at the University of Wales, Newport, while STAR, the Science Technology and Arts Research center, was based at the University of Plymouth in the United Kingdom. These centers were the focus of advanced research on the integration of science, technology and the arts. CAiiA-STAR succeeded in attracting doctoral and post-doctoral researchers whose work transcended conventional subject boundaries. Doctoral candidates working with the center received their degrees from their respective host institutions.

CAiiA-STAR's operation was unique, distinguished by composite sessions conducted in-residence at the host universities and, by invitation, from media centers and institutions in other parts of the world. Doctoral candidates were required to attend three, ten day sessions per year to consult with their advisors, meet and critique their fellows, and perform thesis research. For the remainder of the year candidates worked at their home-based institutions and maintained contact with their advisors and colleagues via the Internet.

\section{The Planetary Collegium}

Unlike CAiiA-STAR, the Planetary Collegium seeks to be independent of any host institution. It resembles its predecessor in its mission: the exploration of human possibility through new integrations of arts, science and technology. The Collegium aims to embody the future in its operation, community, and public presence. To achieve these ends the Collegium will develop synergies with futureoriented industry leaders to ensure both its cultural eminence and fiscal viability. The Planetary Collegium currently resembles the CaiiA-STAR model in operation. As before, it couples face-to-face interdisciplinary dialog with the decentralized, nomadic affordances of an Internetworked community. Unlike CAiiA-STAR, the Planetary Collegium seeks to be independent of any host institution. It resembles its predecessor in its mission: the 
exploration of human possibility through new integrations of arts, science and technology. The Collegium aims to embody the future in its operation, community, and public presence. To achieve these ends the Collegium will develop synergies with future-oriented industry leaders to ensure both its cultural eminence and fiscal viability. The Planetary Collegium currently resembles the CaiiA-STAR model in operation. As before, it couples face-to-face interdisciplinary dialog with the decentralized, nomadic affordances of an Internetworked community.

However, as proposed by Ascott, the Collegium will have attributes quite different from its precursor. [Ascott, 2002] In departing from host universities the Collegium would appear to lack the localized infrastructure needed to conduct its business. In answer Ascott proposes that the Planetary Collegium be a distributed presence, embodied in seven campuses situated strategically around the globe. Each campus would be an infrastructural sub-center - or node - of the Collegium, replacing to varying degrees the amenities of a host institution.

\section{The Collegium Site}

Although the nodes of the Collegium are to be situated in different parts of the world, the Collegium as a whole has no site. It is a virtual organization with no center, only the media and cyberspaces shared by the nodes sustain it. These cyberspaces form the global body of the Collegium. The absence of a physical site frees us to seek a form that unifies the nodes while suggesting a design strategy for their local configuration. Even though the global Collegium exists only in cyberspace, the mixed reality strategy compelled us to assign it a meaningful location with respect to the material world. Consequently the Collegium forms a rough circular disk centered at one of the Earth's poles - for our purposes the North Pole. (Fig. 1) The disk consists of the cyberspaces of the seven nodes, each aligning with the longitude of its physical site on the globe. The polar disk and its directional correspondence to terrestrial locations conduce to the Collegium's planetary role.

\section{Configuration of Planetary Collegium}

Since the Collegium comprises seven nodes distributed about the Earth, the Planetary Collegium's disk is divided evenly into wedges. The disk was divided into eight sections with the intention of leaving the last section empty. This eighth section would accommodate other cyberinstitutions that might collaborate with the Collegium. (Fig.
2) shows a conceptual sketch of a wedge indicating the vertical separation of abstract and concrete spaces and the lateral distribution of public/private spaces (showing an earlier scheme). The sketch shows an arc taken from the disk is a local "instance" of the global program: a Collegium node.

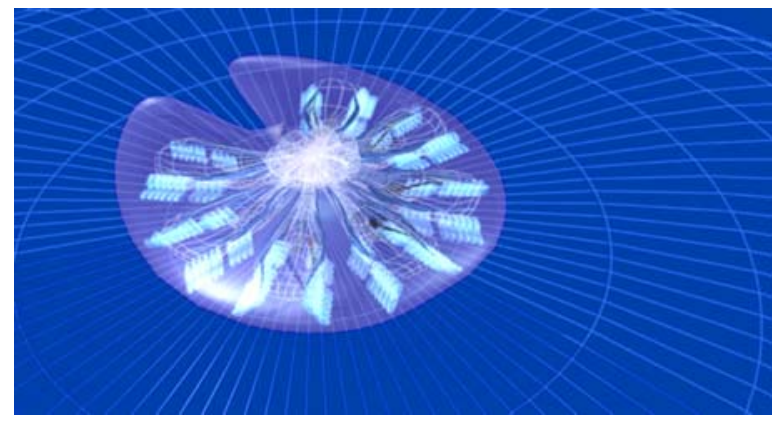

Figure 1. View of Collegium cyberspace as disk located at pole. Image shows final resolution of the design.

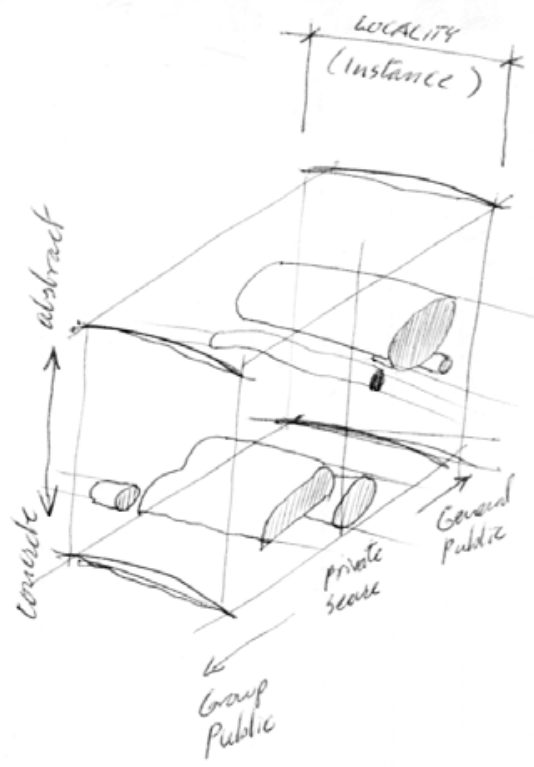

Figure 2. Early conceptual sketch of a Planetary Collegium node. The node is understood to be a segment of the Collegium disk with programmatic extrusions circling the axis. 
At this stage we have a schematic strategy for the spaces of the Collegium's global and local configurations. Although it is subject to refinement, it already has traits that will serve in the next stage of development. These include: 1) the polar orientation of the Collegium and its nodes; 2) the roughly triangular form of the Collegium's constituent nodes; 3) the southern location of most public spaces within the nodes and 4) northern location of most spaces private to the Collegium; 5) that cyberspaces are found at higher elevations than material resource/spaces; and finally 6 ) the metaphoric use of space (form and location) within complex. We used metaphors in developing a mental framework - or mnemonic frame - for the spatial understanding of the occupant/visitor. The frame helped establish relationships between physical and cyberspaces so viewers could infer them directly or through technology. The observer's mental completion of the scheme is crucial
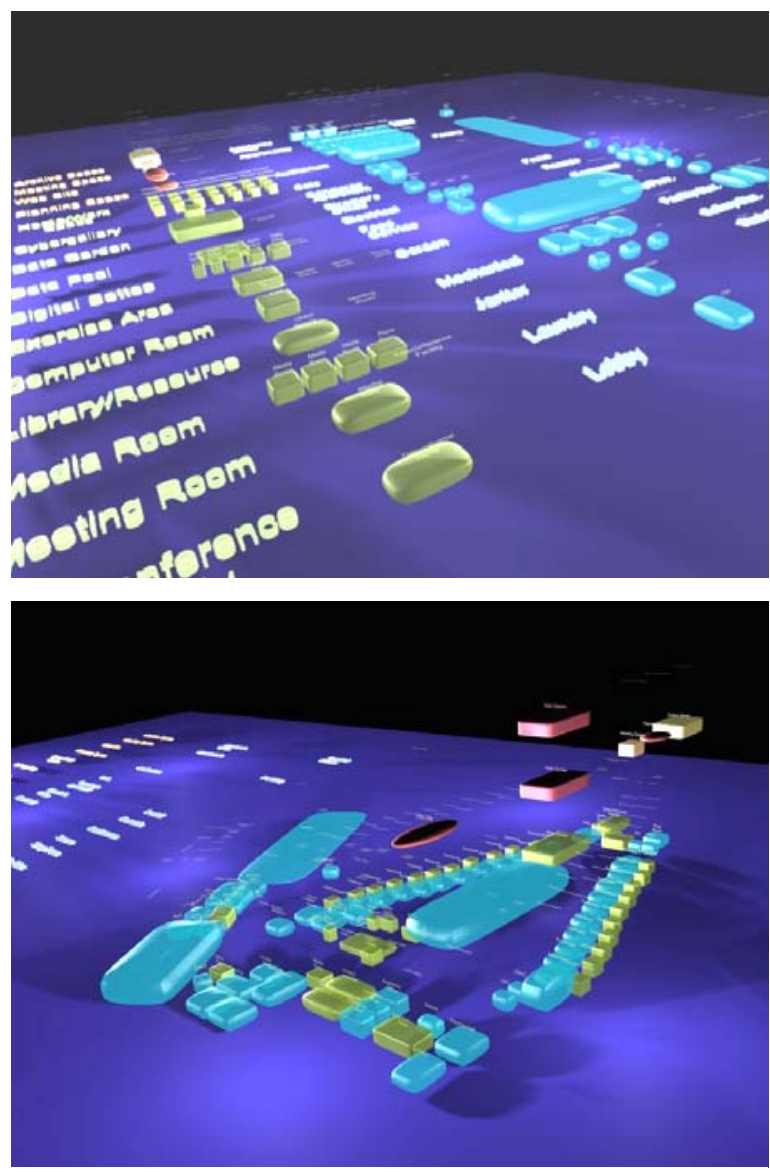

Figure 3. Physical and virtual programmatic elements, left, with node massing diagram. to the project's mixed reality, and viewer's engagement with the Collegium.

The configuration shown fits the program to an imaginary site - one that challenges the symmetry of the original node triangle. (Fig. 3) Cyberspaces typically float above the project while most of the cybrids (hybrids of physical and virtual structures) and buildings rest on or below the ground. The triangle of the node - a reference to its cyberspace origin - is framed by symmetrical rows of dormitories flanking the central data garden. Public amenities, auditorium, gallery and offices occupy the southern end of the triangle, while functions private to the Collegium are at its northern peak. In section the project dematerializes as it rises from the earth with only cyberspaces at its polar and upper extreme. The buildings emerge from the local landscape, cyberspaces are aerial, and mixed-reality cybrids mediate between the two.

The image below shows a further development of the scheme. (Fig. 4) It shows a larger, more definitive massing for the node's activities. Though still at a preliminary stage the design takes a more architectural form, consolidating allied functions and articulating the cyberspaces within the scheme. Though still at a preliminary stage the design takes a more architectural form, consolidating allied functions and articulating the cyberspaces within the scheme.

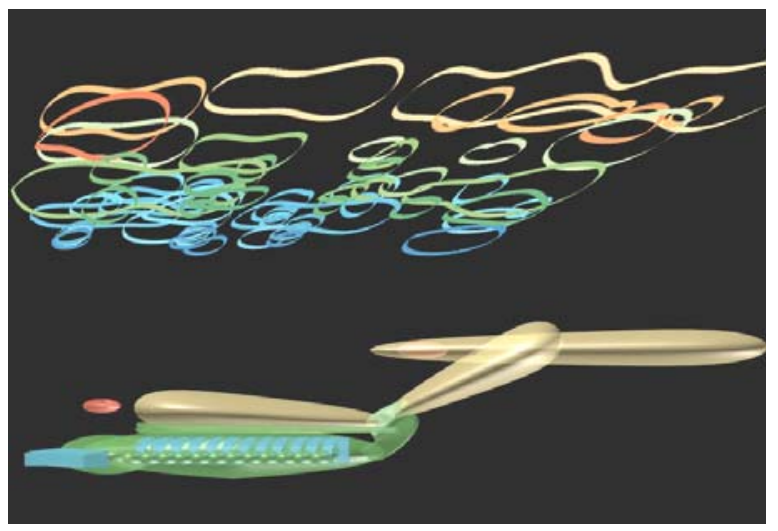

Figure 4. Developed programmatic massing model of node, below, compared with programmatic extrusion diagram above. Refer to figure 2 . 


\section{Linking a Node to the Collegium Disk}

The images below show the massing related to other nodes within the Collegium disk. (Fig. 5 and 6) The configuration replicates the physical public buildings as though all material node sites were the same. This would not be the case since materialized nodes would have slightly different physical configurations in each case. It may seem curious that the physical elements of the scheme should appear in the cyberspace of the Collegium. This is because, effectively, the project's cyberspace (as CAD, CAM, digital files) precedes any actual building. The building is only one manifestation of the project cyberspace - arguably one of many print-outs.

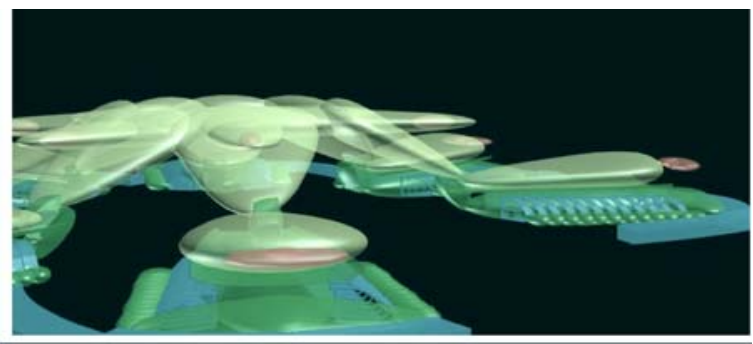

Figure 5. Programmatic massing of Collegium nodes within disk.

This cyberspace offers important archival and operational resources. Moreover the Collegium can use it as a digital setting or interface for telecommunications. In this way the digital/spatial record of construction may find a new life at the service of Collegium activities.

These images present the programmatic massing shown previously within the overall disk of the Collegium. Here we see the interlinking of nodes' cyberspaces at the hub of the Planetary Collegium disk. More public and physical spaces (green and blue) are found at the edges of the disk; private Collegium functions (gold) are nearer the center. Virtual visitors to the Collegium's disk would be able to enter the cyberspaces of the dispersed nodes. Conversely, when residents to a physical node see its virtual counterpart they would also see the rest of the Collegium disk- and be present within it to others.

This linkage would depend on the Collegium's simulation being constantly updated by the nodes. The corroborative display of this information integrates material, simulated and mental space, resulting in the Collegium's comprehensive space. Figures 7, 8, and 9 show the relationship between a node and the Collegium's disk. The shadow of the Collegium disk is effectively present at all node sites.

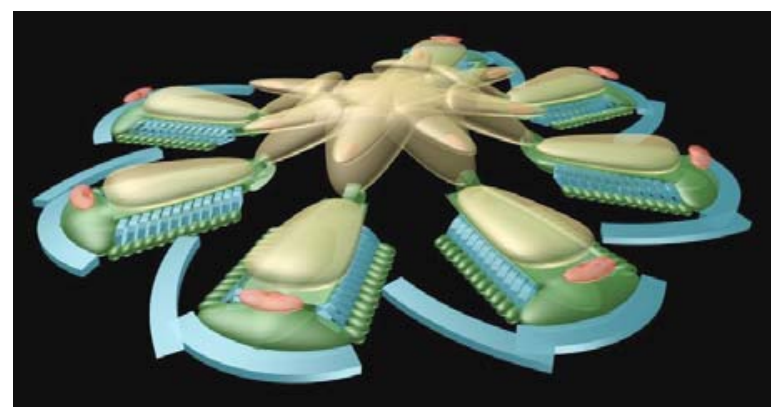

Figure 6. Programmatic massing of Collegium nodes within disk.

At this stage we have developed the programmatic layout of the Collegium, its general configuration, and that of its constituent nodes. The geometry helps to establish a mnemonic frame for the Collegium, so that it may be relayed in the Collegium's literature, graphics, operation and rituals. While the triangular nodes are components of the overall disk, they individually represent local built nodes on the ground. Polar orientation also relates all nodes to the Collegium's polar disk despite the nodes' dispersed locations.

\section{Cybrids and Buildings}

In order to estimate the effect of simulation on different architectural programs, the design would take on the detailed programs of several building types. Each Collegium node would include the following buildings types or - as products of mixed reality - cybrids:

1. An entry structure with offices and shop

2. A display gallery

3. An auditorium

4. A café with outdoor pool

5. Dormitories for visitors and residents

6. A library/resource center

7. An observatory, a structure for public events/presentations 
Each cybrid/building would have its own attendant cyberspace - a subset of the Collegium node's local cyberspace. These cyberspaces incorporate 1) the data model that precedes the cybrid's construction, 2) simulations of the constructed spaces, 3) ancillary social/functional spaces to support the resource/space, 4) data displays relating to the use of the physical structure
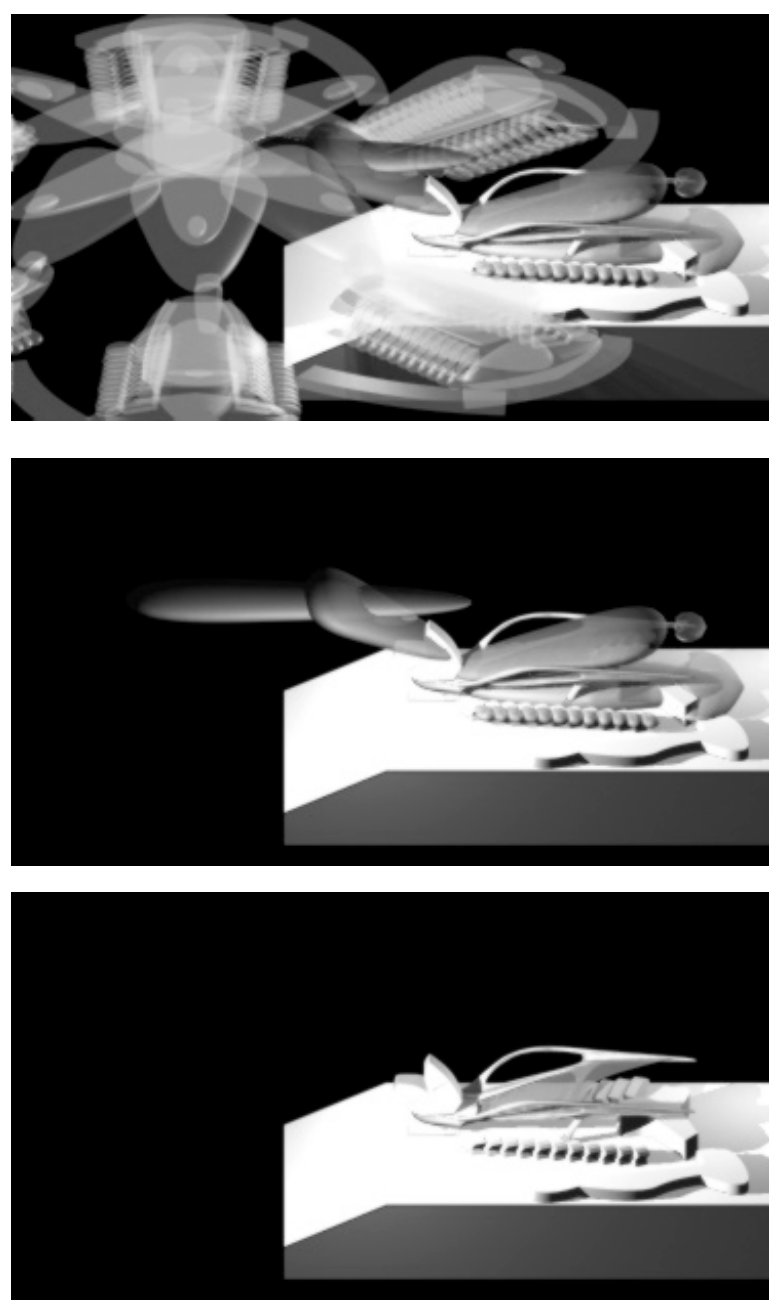

Figure 7 through 9 show from the top a node linked to the Collegium disk, the node's cyberspace and cybrid/buildings, and finally the node's buildings at bottom. It is tempting to think of the physical construction as a distillate of antecedent cyberspaces. Note that these images are still schematic representations showing envelopes indicated previously. The configuration of the built forms is also preliminary. and building systems, 5) audio-visual communications and data displays of occupants and activities. All these data, represented spatially and audio/visually would be updated as necessary. Since the cyberspaces would serve social interaction, audio and visual communications data would have highest priority and consequently be updated continuously. The informational demands of the cyberspaces would require sensors, actuators, digital relays and processors to be part of the final construction. Although each cybrid supports interaction often attributed to "intelligent buildings," the purpose of such interactive technology is mainly to sustain for the occupant an integrated cyberspace within and around the structure.

\section{Relating Physical and Cyberspaces}

A cybrid's cyberspace and physical structure reinforce one another. All effects, physical or simulated, corroborate each other to create a comprehensive space for users. This helps to situate them within the project's extended phenomenal environment. For instance, an on-line visitor to a cybrid would see not only the configuration of the cyberspace but evidence of the material construction at the several Collegium nodes. Conversely, the physical elements of cybrids would hint at their contingent cyberspaces. Experiencing the cyberspace is not limited to viewing screens and wearing head-mounted displays. Sound and light projections would manifest the cyberspace to the unaided observer. Buildings would hint at invisible presences through fragmented, overlapping or bracketing configurations. Technology could help this overlap as well. Figure 10 shows how laser projection may complete fragmented geometries.

Such techniques are well suited to cybrids since the result employs both material and simulated elements. Another technique uses material construction - glass, mirrors, projection surfaces - to redirect projections thereby extending the phenomenal space of the composition. This last technique recalls the 19th century illusion, Pepper's Ghost. In an update laser projections would replace the actors in the orchestra pit. Their reflection in the glass would appear to hover on stage beyond. This effect manifests the fictional space of the stage - our cyberspace - extending a building's space beyond the mirrored glass. Like the laser projections, this illusion is environmental and does not encumber the viewer with special glasses or other worn displays. 


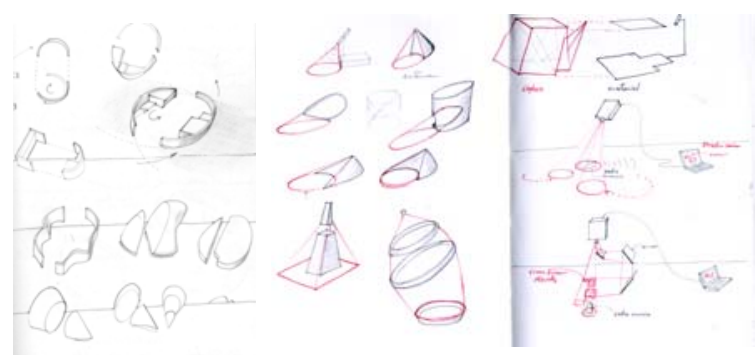

Figure 10. These sketches show ways in which physical objects may suggest the presence or better absence - of another form that completes a composition. Red lines indicate laser projections that would delineate the absent forms.

\section{Refining the Conceptual Frame}

Reconciliation and corroboration of effects depend on viewers' expectations and experiences within the Collegium. Now, at a local scale, we need to establish a frame for relating parts to the whole. The symmetrical frame is an identifying, orienting feature of the Collegium that situates the effects of the Collegium for the observer. In this way the physical and simulated attributes of a Collegium node may be mnemonically available to the observer even when off-site or off-line. Yates, Spence and others have described such a use of memorable features in the creation of mnemonic structures, or memory palaces. [Yates 1966] [Spence 1985] Traditional memory palaces were created by memory arts practitioners, often with reference to available environments, city plans, buildings - even bodies. The present project, the Planetary Collegium, was to exist most effectively in the mind and experience of the user. It draws from both mnemonic traditions and recent psychological research to create an experiential frame for the user.

A reinterpretation of the geometry allows us to further develop this frame. An aerial view of the configuration discloses a roughly anthropomorphic image with the head at the apex of the triangle and the feet at the base. This may appear to be an accident of geometry - given the wedge shape and symmetry - but it reinforces other aspects of the Collegium and its nodes. For example the current node scheme weighs the cyberspaces toward the head of the triangle and more physical structures toward its base - or feet. This anthropomorphism also reflects back to the Collegium disk which now connotes a communal embrace as well as a cellular organism. Although, pushed to an extreme, this interpretation risks uniform utopianism, the nodes are physically in vastly different parts of the world. They would inevitably bear the stamp of their own cultural identity within the project.

\section{Elements of the Node}

The cybrid programs mentioned previously superficially resemble those of conventional buildings. The descriptions below show how each cybrid integrates physical and cyberspaces in its use. The empirical modes offered by each cybrid are shown in an accompanying table. So too are the roles of the various spaces within the cybrid's configuration.
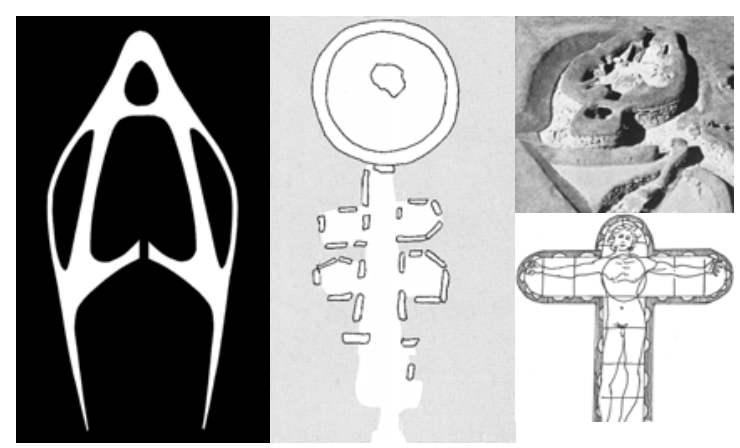

Figures 11, 12, 13, 14. The structural diagram of the Collegium resembles an anthropomorphic form in the image on the left. The image in the middle is the plan of a longbarrow in Notgrove, England, based on the form of an earth deity. Similarly the photograph on the upper right shows the earth deity manifested in a temple at Skara Brae, Orkney c. 2100 B.C. The diagram below it

\section{The Node Site}

The site here presented is fictitious, situated in a tropical climate atop a small knoll. The structures and spaces situated on the site are oriented longitudinally toward the north (or south) pole. (Fig. 15) The node's axis of symmetry connects the poles, while its triangular configuration points to either the North Star or the Southern Cross. For purposes of this discussion we will assume that the project points north.

The lower elevations of the site accommodate the public/local functions of the node, while the upper levels 
typically serve the Collegium, its faculty and researchers. Special events and festivals open the upper levels to public view. The site is reflected in cyberspace to orient the node's attendant cyberspaces. Upper levels typically serve the Collegium, its faculty and researchers. Special events and festivals open the upper levels to public view. The site is reflected in cyberspace to orient the node's attendant cyberspaces.

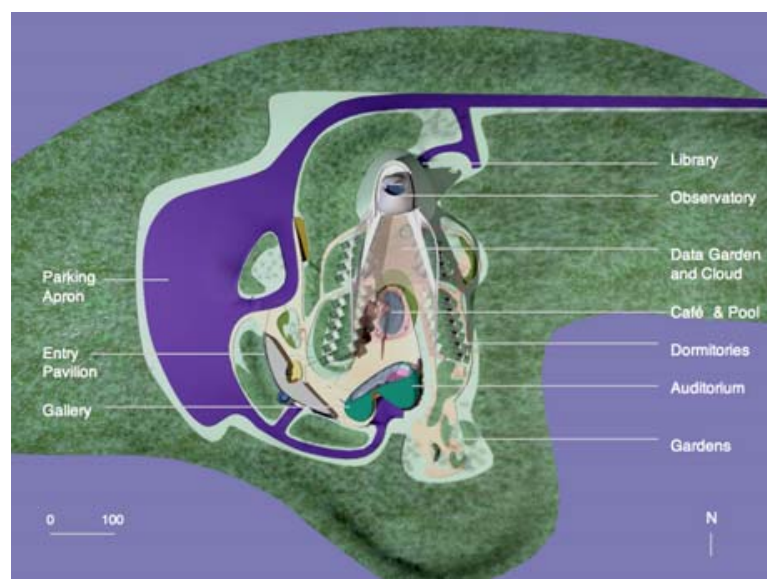

Figure 15. Site plan of physical node showing locations of buildings.

Visitors access the physical site by a road that takes them past the Observatory to parking and a transit stop/drop off. Visitors walk along a promenade that passes in front of an entry pavilion, the gallery/auditorium, and the pool-side café. The earth to either side of the promenade is excavated to suggest the cyberspaces associated with each structure. The culmination of the promenade is the Data Garden, a two level space that incorporates a pool, a garden terrace, an upper-level space for engaging virtual and mixed reality, an outdoor conference table and the entry to the node's library building. The Data Garden forms the centralized court of the Collegium node with its lower level open to informal public activities; the upper is used for research and node-related affairs. It is called the Data Garden because it comprises a variety of natural/artificial outdoor environments equipped for benign surveillance and multimodal display. The displays - whether on screens and speakers, projected, or worn - corroborate one another through a shared data base, and result in a consistent cyberspace that overlays the physical site. The Data Garden itself is partially covered by a canopy, the Data Cloud, that spans between two bridge-like structures emanating from the Observatory. This canopy shades parts of the Data Garden and, at night, can be used as a projection surface. Pathways on the east and west sides of the node allow for informal meeting and exercise. Portions of these pathways form lobes that support virtual and mixed reality experiences. An access road also encircles the southern part of the node to provide service to the public buildings. The rest of the site is forested and left in as natural a state as possible.

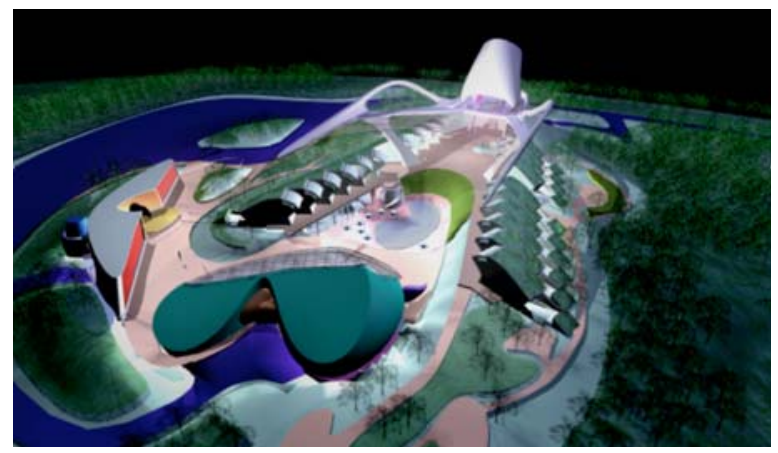

Figure 16. Overview of the physical structures of a Collegium node.

\section{Entry Pavilion}

The Entry Pavilion is the first structure a visitor encounters upon approaching the Collegium node. (Fig. 17) This partially buried structure stands between the transit stop and the gallery nearby. Physical spaces include a small provisions shop, mail center, loading dock and management offices. The cellar level houses material archives and storage for both the shop and offices. The pavilion's cyberspaces overlap the structure spatially and programmatically. The shop, mail center and offices extend as cyberspaces onto the promenade. The office cyberspace extends into a link connected to the Gallery. These cyberspaces collectively form a spatial Web site that is the on-line gateway to the Collegium node.

\section{The Gallery}

Near the entry pavilion in a structure shared with the auditorium is the Collegium node's art Gallery. The upper level of the Gallery extends toward the lobby of the auditorium past an elliptical structure containing an office, loading dock and projection booth. The lower level of the gallery includes restrooms, two display spaces and an ambulatory gallery that wraps around the lower level of the auditorium. The upper gallery parallels the external 


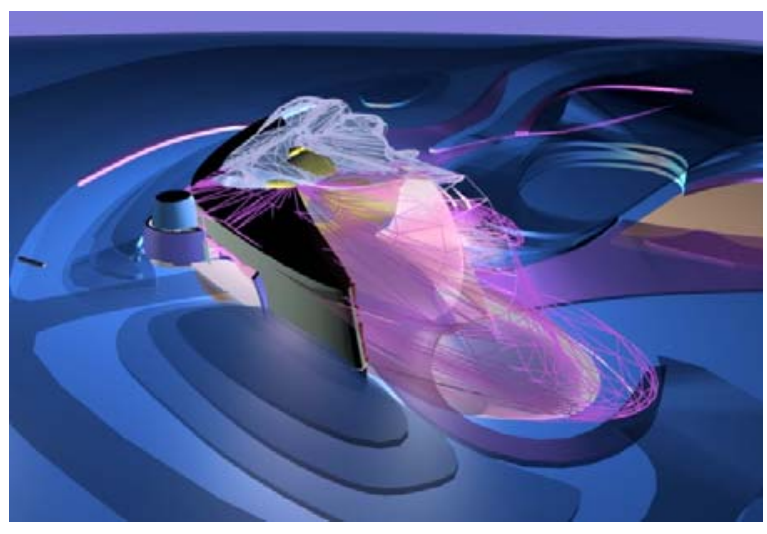

Figure 17. View of Entry Pavilion with associated cyberspace.

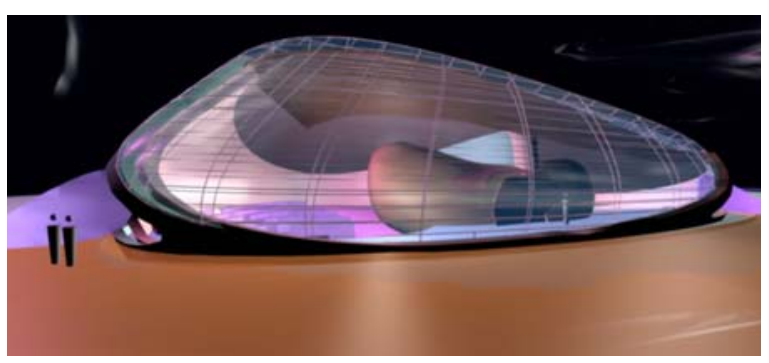

Figure 18. View of Auditorium/Gallery structure showing glazing.

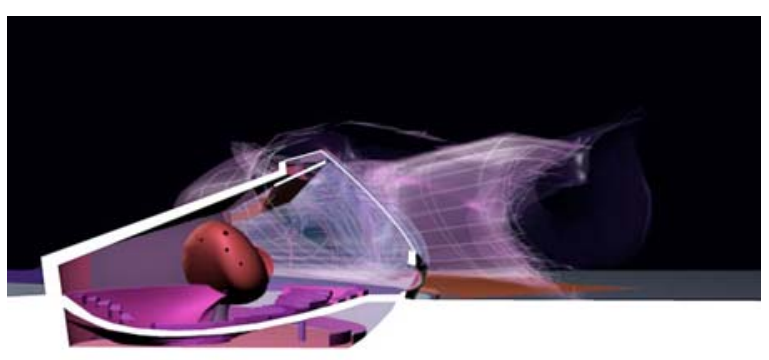

Figure 19. Section of Auditorium/Gallery structure showing seating and attendant cyberspace.

promenade with a convex, curved glass façade. (Fig. 18) The specially configured façade projects the illusion of an attached space beyond the glass through use of digital displays and the reflective qualities of the glass itself. This Pepper's Ghost illusion manifests the gallery's cyberspace as a mixed reality outside the building. (Fig. 19) The effect requires no encumbering technology for the observer, however it can only be observed from within the building.
Seeing the ghosts and virtual objects while standing outside the gallery requires the observer to use other forms of display including headsets or screens.

\section{Auditorium}

The Collegium node's public auditorium is housed in the same building as the gallery. It shares the upper level lobby along with the mixed reality display that extends to the promenade outdoors. (Fig. 18 and 19) The auditorium has facilities for projection and audio-visual display and shares restrooms and loading facilities with the gallery. The auditorium cyberspace is shared with the gallery and supports teleconferences and mixed reality presentations. Experiencing these mixed realities requires screens, projections and/or head-mounted displays. The illusion made possible by the building façade does not extend to its interior spaces. The auditorium and gallery are both public gathering spaces and perform an important service to the node's host community. It is anticipated that both gallery and auditorium would be used for non-Collegium activities throughout the year. In combination with the Café and Data Garden the Gallery/Auditorium forms an inviting venue for social and cultural interaction on both local and global scales.

\section{Café and Pool}

The Café faces out onto a centralized swimming pool on the lower level of the Data Garden. The café itself is subterranean and consists in an informal eating area, a kitchen and a laundry facility. A rear access leads to an underground passage to the traffic turnabout. The dining area of the Café includes tables near the pool. (Fig. 19) The cyberspace of the Cafe supports social interaction at both the tables and in the pool itself. Teleconferencing pods surround two of the tables on the terrace and a large table

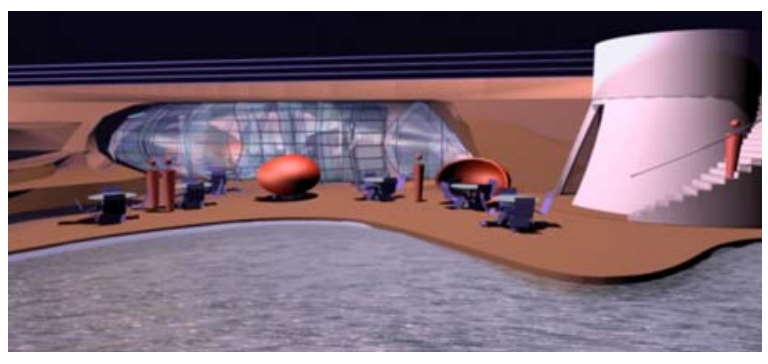

Figure 20. View of Café façade, changing tower (right), terrace and data pool. 
in the café itself. Projections onto the pool reflect upward onto the canopy above. Submarine projections onto the pool's interior turn the pool into an augmented environment. All illusions projected onto these surfaces are consistent and tributary to the café's cyberspace.

\section{Housing/ Dormitories}

Flanking the central Data Garden are twenty-two dormitories which form long, berm-like walls on the east and west sides of the node. As noted above, activities on the upper level of the node are usually private to the Collegium except for festivals and special events. The central space lying between the dormitories is the upper level of the Data Garden. This area contains an open space for engaging virtual and mixed reality displays, an outdoor conference table, and - to the north - the entry to the node's Library/Resource Center.

Each dormitory unit has a conversation area, sleeping loft, kitchenette and bathroom. (Fig. 21) It is entered from the Data Garden, as well as through sliding-doors bordering a small terrace. Each terrace in turn opens onto a network of paths that embrace the node complex. The dormitory unit roof is sod-covered to provide protection from the sun. The overhead canopy of the Observatory offers additional solar protection.

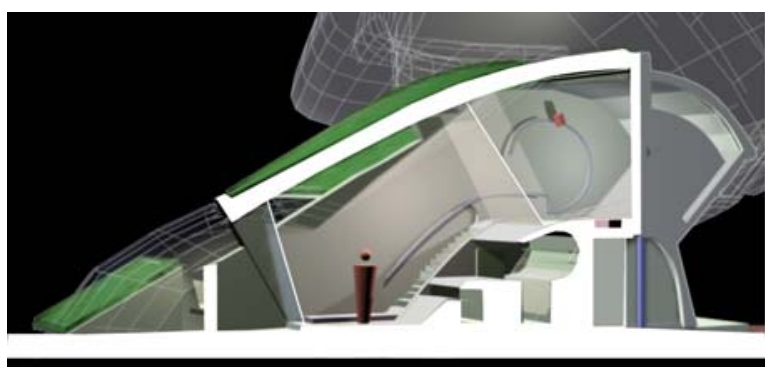

Figure 21. Section through dormitory unit. Note cyberspaces extending beyond lower living area and above vault of upper sleeping loft. Looped railing supports a mobile laser projector that may shine on scrim or on ceiling vault.

The dormitory cyberspaces engage the conversation and sleeping areas. The glass wall facing the terrace is tilted outward. The angle of the tilt lets observers on the inside see the reflection of a projection scrim situated over the kitchen area. Projections on this scrim from the sleeping loft appear to be suspended outside the conversation area on the terrace. The terrace itself has a bench facing the glass wall. This bench would be the apparent seating for visitors projected from the Internet. The upstairs sleeping area has a vaulted ceiling that is also a projection surface. The same projector used in the terrace illusion can be rotated to project onto the vault above. Using bedside controls, the user can navigate the environments that subtend his and her viewing angle. The experience would resemble that of being in an IMAX theater, but in a horizontal position.

\section{Library/ Resource Center}

At the north end of the node is the partially buried Library/Resource Center. (Fig. 22) The library building forms a base for the observatory above, and appears to be a conical hill from outside the complex. It is entered from a courtyard at the north end of the Data Garden. Inside is an information desk, computer area and stacks. Both east and west wings of the Library contain restrooms, offices and conference rooms. These last spaces are occupied by Collegium faculty and researchers. The lower level of the Library is occupied by a loading dock as well as mechanical, systems and computer support for the Collegium node. There is also a computer facility for node operation and research located directly under the court. A stairway rises from the courtyard and over the library to the landing of the Observatory.

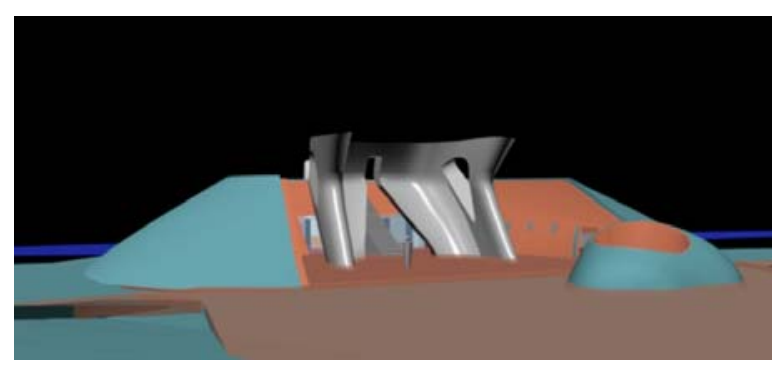

Figure 22. View of Library/Resource Center showing teleconferencing table in foreground and legs and stair of the Observatory within the entry court.

The Library/Resource Center's cyberspace is largely dedicated to the Library function. It includes a navigable database of materials and works used by the researchers, and forms a virtual, ever-changing extension from the upper computer area of the building toward the north. The cyberspace of the Observatory extends downward into the courtyard and out to the Data Garden. Cyberspaces of the 
research area are generally specific to the research done at the time.

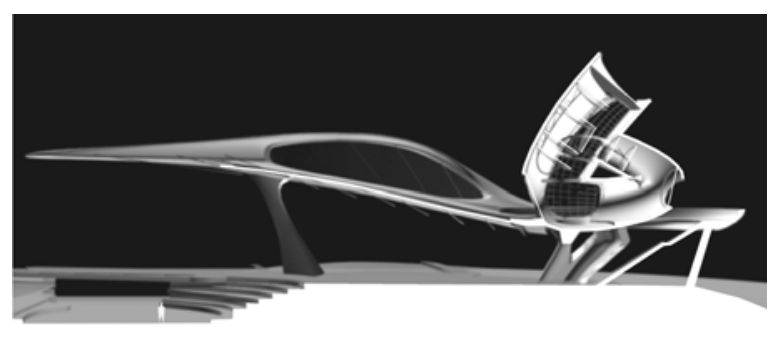

Figure 23. Section through Observatory and tensile cloud structure. Note optical assembly in fly structure of Observatory.

\section{The Observatory}

The Observatory is an event structure that surmounts the Library at the north end of the Collegium node. Emanating from the Observatory are bridge-like structures supporting a canopy, called a Data Cloud, that can hold the weight of participants and observers. (Fig. 23) Both the Observatory and cloud support image projection and directional sound displays. The Observatory itself is an optical instrument for observing mixed reality. Its configuration is the product of optical alignments/angles necessary to produce simulations that appear to occupy the cloud to the south and the sky to the north. Thus, the Observatory is a link between the cyberspace disk of the Collegium to the north and the southern extended agora of the Collegium node - an agora comprising the Data Garden below and the cloud above.

The floor of the Observatory is entered through doors on the east and west. To the south they face a large angled glass looking out toward the canopy. To the north another, smaller glass looks away toward the north sky. Rising at an angle at to the south is a fly space that contains several elliptical scrims. Unlike scrims of conventional theater, these are fixed and face the angled glass below. The armature that supports the scrims also holds a mirror at its upper limit and several data-driven laser projectors at the intervals between scrims. A similar armature/scrim system arises from the north glass, angling back to the south and penetrating the aforementioned fly space.

The cloud is also a scrim, although one that is more opaque than those in the Observatory. It holds the weight of observers/participants and is accessed from the supporting bridge structures, or wings, to the east and west. The cloud receives images projected from below using color laser projection. The relative opacity of the cloud scrim protects viewers' eyes from the laser light. Images projected onto its surface may be conventional images, or they may be markers for use in creating a mixed reality using Billinghurst and Kato's ARToolkit or similar systems. [Billinghurst and Kato 1999] Projections onto the northern portion of the scrim can also be reflected in the observatory's glass to present images of remote participants in the hall beyond. This allows outside observers to participate in an unencumbered mixed reality. They would otherwise be limited to the scrim and worn displays when out of doors. (Azuma 1999) (Neumann et al 1999)

\section{Mutability and Flexibility of Cyberspaces}

The Collegium node is a cybrid whose physical domain is local while its cyberspace is part of the Collegium's global disk. At a smaller scale, every component of the node is also a cybrid. Each of these sub-cybrids - Entry Pavilion, Gallery, Auditorium, Café, Dormitory, Library, and Observatory - has a cyberspace attendant to its physical structure that serves the larger program of the Collegium.

Cyberspace joins the programmatic components of the scheme at various scales. At the largest scale the cyberspace attending a node is the entire cyberspace of the Collegium. At a smaller scale the various cyberspaces of the node's sub-cybrids merge, abut, and overlap one another. Although the contents of each of these smaller cyberspaces may be programmatically distinct, it would be possible for them to share information. In this way, an avatar leaving the auditorium for the café will successively appear in the adjacent cyberspaces. The cyberspaces may also merge with one another to form new cybrid groupings. (Anderson and McGrath 1998) For instance the library cyberspace may join with that of other Collegium nodes to create a larger library space. More radically, the sub-cybrids may join into new configurations by heterogeneously sharing their cyberspaces. A dormitory cyberspace, for example, could join with that of a present or remote auditorium or library. This could conceivably overcome the inconveniences of physical location. It would be the spatial equivalent of a telephone call. 


\section{Conclusion}

The Planetary Collegium design shows how architecture can fully take advantage of simulated and actual space. The planning strategy, intended to create a mnemonic structure for the occupants, made use of several overlapping metaphors to orchestrate the different scales of the project. The focus here was to make the space meaningful so as to situate visitors and occupants, a strategy that would radically differ from less dimensionalized projects. Ancient techniques of symbol, metaphor, and memory palaces could become important tools for addressing and unifying our increasingly mixed realities.

\section{Bibliography}

Anders, Peter. 2004. A procedural model for integrating physical and cyberspaces. Doctoral dissertation, University of Plymouth, U.K.

Anders, Peter. 2003. Towards comprehensive space: A context for the programming/design of cybrids. In proceedings of ACADIA 22, 23-26 October, Indianapolis, Indiana, ed. Kevin R. Klinger, pp. 160-171.

Anderson, Ben, and Andrew McGrath. 1998. Strategies for mutability in virtual environments. In Virtual worlds on the Internet, ed. John Vince and Rae Earnshaw, pp. 123-134, Los Alamitos, Cal.: IEEE Computer Society.

Ascott, Roy. 2002. The Planetary Collegium. Unpublished.

Azuma, Ronald. 1999. The challenge of making augmented reality work outdoors. In Mixed reality: Merging real and virtual worlds, ed. Y. Ohta, H. Tamura, pp. 379-388. New York: Springer-Verlag.

Benedikt, Michael (ed.). 1991. Cyberspace: First steps. Cambridge, Mass.: MIT Press.

Billinghurst, Mark, and Hirokazu Kato. 1999. Collaborative mixed reality. In Mixed reality: Merging real and virtual worlds, ed. Y. Ohta, H. Tamura, pp. 261-280. New York: Springer-Verlag.

Neumann, U., S. You, Y. Cho, J. Lee, J. Park. 1999. Augmented reality tracking in natural environments. In Mixed reality: Merging real and virtual worlds, ed. Y. Ohta, H. Tamura, pp. 101-130.

New York: Springer-Verlag.

Schmitt, Gerhard N. 1993. Virtual reality in architecture. In Virtual worlds and multimedia, ed. N. M. Thalmann and D. Thalmann, pp. 85-97, New York: John Wiley \& Sons.
Spence, Jonathan D. 1984. The memory palace of Matteo Ricci. New York: Viking Penguin.

Yates, Frances. 1966. The art of memory. Chicago: The University of Chicago Press. 